\title{
Evidence For Terror Management Theory: I. The Effects of Mortality Salience on Reactions to Those Who Violate or Uphold Cultural Values
}

\author{
Abram Rosenblatt and Jeff Greenberg \\ University of Arizona
}

\author{
Sheldon Solomon \\ Skidmore College
}

\author{
Tom Pyszczynski \\ University of Colorado, Colorado Springs
}

\author{
Deborah Lyon \\ University of Arizona
}

\begin{abstract}
On the basis of terror management theory, it was hypothesized that when mortality is made salient, Ss would respond especially positively toward those who uphold cultural values and especially negatively toward those who violate cultural values. In Experiment 1, judges recommended especially harsh bonds for a prostitute when mortality was made salient. Experiment 2 replicated this finding with student Ss and demonstrated that it occurs only among Ss with relatively negative attitudes toward prostitution. Experiment 3 demonstrated that mortality salience also leads to larger reward recommendations for a hero who upheld cultural values. Experiments 4 and 5 showed that the mortality salience effect does not result from heightened self-awareness or physiological arousal. Experiment 6 replicated the punishment effect with a different mortality salience manipulation. Implications for the role of fear of death in social behavior are discussed.
\end{abstract}

Although it is evident that individual behavior is greatly affected by one's culture, relatively little is known about the forces that promote allegiance to particular cultural worldviews. Terror management theory (Greenberg, Pyszczynski, \& Solomon, 1986; Solomon, Greenberg, \& Pyszczynski, 1989, in press) posits that cultural conceptions of reality serve the vital function of buffering the anxiety that results from awareness of human vulnerability and mortality. Consequently, people are highly motivated to maintain faith in the cultural conceptions of reality to which they subscribe and to defend these conceptions against threats. The purpose of the research reported in this article was to test several hypotheses derived from terror management theory concerning reactions to those who uphold and violate cultural worldviews.

Terror management theory is based largely on insights gleaned from Ernest Becker's (1962, 1973, 1975) attempts to synthesize contributions from the various social science disciplines into a coherent conception of human motivation and behavior. According to Becker, sophisticated human intellectual abilities lead to an awareness of human vulnerability and mortality, and this awareness creates the potential for overwhelming terror. As these abilities evolved, cultural worldviews began to emerge. The potential for terror put a press on evolving conceptions of reality such that any worldview that was to survive

\footnotetext{
We would like to express our appreciation to Lisa Williams for conducting Experiment 5.

Correspondence concerning this article should be addressed to Jeff Greenberg, Department of Psychology, University of Arizona, Tucson, Arizona 85721.
}

needed to provide a means of managing this terror. The conception of reality espoused by any given culture is thus the basis of a cultural anxiety-buffer that serves to protect the individual from the anxiety that results from awareness of his or her vulnerability and ultimate mortality. ${ }^{\prime}$

According to the theory, however, protection from anxiety requires that one achieve a sense of value or self-esteem within the cultural context. This is because the culture promises security only to those who live up to the cultural standards of value. Cultures provide this security in two ways: first, through conceptions of the world as a just place; in a truly just world, bad things would not happen to good people. Second, cultures promise real and symbolic immortality to those who live up to the standards of value; real immortality via religious concepts, and symbolic immortality via permanent contributions to the death-transcending culture. From this perspective, the cultural anxiety-buffer consists of two components: (a) belief in the validity of a cultural worldview and the standards and values associated with that worldview, and (b) belief that one is meeting or exceeding those standards and values. Thus, the cultural worldview provides a context within which an individual can conceive of him- or herself as a valuable participant in a meaningful world, and thus function with equanimity in the face of his or her ultimate mortality. ${ }^{2}$

\footnotetext{
${ }^{1}$ We are not claiming that this is the only function of the cultural worldview, but rather that it is a very important one.

${ }^{2}$ A complete exposition of terror management theory, including a developmental account of how the two components of terror management acquire their anxiety-buffering properties, would go far beyond the scope of this article. For a thorough presentation, see Greenberg,
} 
Unfortunately, the cultural anxiety-buffer requires continual bolstering and defense against threat. In their daily lives, people are constantly confronted with reminders of the potential for pain, aversive experience, and death. One need only pick up a newspaper or turn on the television to encounter such reminders. In addition, because cultural worldviews are essentially socially constructed fictions, they are always vulnerable to threat by incoming information and require constant social validation. Given that people rely on social consensus to instill confidence in their conceptions of reality (cf. Festinger, 1954; Kelley, 1967), the diverse array of beliefs, values, and behaviors to which people are exposed make it difficult to sustain faith in any particular worldview or in one's place in it. Terror management theory, therefore, posits that people will respond positively to those who bolster their cultural anxiety-buffers and negatively to those who threaten their cultural anxiety-buffers.

Clearly, people react negatively to those who violate cultural norms and values (e.g., Miller \& Anderson, 1979; Schachter, 1951). The research reported in this article was specifically focused on the terror management function of reactions to such deviance. From a terror management perspective, negative reactions to moral transgressors occur because such deviance implicitly threatens the validity of one's own beliefs and values and the cultural conception of reality from which they are derived. When moral principles are not followed, it implies either that the principles may not be universally valid or that the transgressor is evil. Rather than considering the possibility that the moral principle is invalid, people generally prefer to view transgressors as evil; consequently, it is generally agreed that those who break cultural rules must be punished.

To the extent that negative reactions toward moral transgressors are rooted in the implicit threat to the cultural worldview, it follows that such reactions should be intensified when people are reminded of the issues from which their worldviews serve to protect them. The six experiments reported in this article were designed to assess this proposition. Our general hypothesis was that when people are reminded of their own mortality, they are especially motivated to maintain their cultural anxietybuffer, and thus are especially punitive toward those who violate it and especially benevolent toward those who uphold it.

\section{Experiment 1}

In our first experiment, we assessed reactions to a moral transgressor after subjects' own mortality was briefly made salient. More specifically, we asked municipal court judges to set bond for an alleged prostitute, on the basis of the type of information they typically use to make such judgments. The charge of prostitution was chosen because it emphasized the moral nature of the alleged crime. Immediately before receiving information about the case in question, mortality was made salient to half of the judges by asking them to fill out a brief open-ended questionnaire concerned with their thoughts and feelings about the prospect of their own death. Municipal court judges were used as subjects both to enhance the external validity of the

Pyszczynski, and Solomon, 1986, or Solomon, Greenberg, and Pyszczynski, 1989. findings and to assess whether our hypothesized effect would occur using individuals trained to arrive at decisions based on the rational evaluation of factual information according to the law.

\section{Method}

Subjects. The subjects were 15 male and 7 female municipal court judges from a large southwestern city. The judges volunteered to participate in the study.

Procedure. The experimenter explained to the contact judge (whose data were not used) that she was interested in the relation between personality, attitudes, and bond decisions. The judge then distributed the packets of materials and instructed the other judges to complete them in order and return them to a collection box in the judge's chambers as soon as possible. Of the 24 judges given the materials, 22 returned them.

The packet of materials contained an instruction cover sheet, several filler questionnaires that were included to support the cover story and disguise the true purpose of the study (the Life Change Scale, T. H. Holmes \& Rahe, 1967, and the Beck Depression Inventory, Beck, 1967), the mortality-salience manipulation, the Multiple Affect Adjective Check List (MAACL; Zuckerman \& Lubin, 1965), a case brief for the accused prostitute, and a bond assessment form. The instructions told subjects not to look ahead and to complete the forms consecutively in one sitting. Subjects were also assured of their anonymity and asked not to talk about the study with anyone else.

The mortality-salience manipulation was accomplished by inserting the Mortality Attitudes Personality Survey into the packets for half of the subjects. The survey is a brief two-item, open-ended questionnaire designed specifically for use in this study. First, it explains that it is a new form of projective personality assessment in which open-ended responses to questions about death are content analyzed. Then it asks subjects to write about (a) what will happen to them as they physically die, and (b) the emotions that the thought of their own death arouses in them. Control subjects were not given this questionnaire.

The mortality-salience manipulation was followed by the MAACL, which was included to assess any affective reactions to the manipulation. The MAACL was scored for positive affect, hostility, depression, and anxiety (Zuckerman \& Lubin, 1965).

The case brief and bond assessment forms that followed were virtually identical to those typically submitted by pretrial services to the judges (the contact judge helped in their preparation). The case brief stated the arresting charge (prostitution) and the defendant's address, employment record, and length of residency. The prosecutor noted that, because of the defendant's lack of established community ties and given that he could not verify the preceding information, he recommended against releasing the defendant on her own recognizance. A copy of the citation that was (hypothetically) issued to the defendant was also included. This citation gave basic arrest information such as the location and date of the crime, the arresting officer, and the arresting charge. The case brief was followed by a form that asked the judges to set bond. This form explained that the defendant had had a prior prostitution conviction 6 months ago and had no failures to appear in court.

\section{Results and Discussion}

A one-way analysis of variance (ANOVA) on subjects' bond assessments revealed the predicted effect, $F(1,20)=4.70, p<$ .05 . Judges in the mortality-salient condition assigned the defendant a much higher bond than did judges in the control condition ( $M s=\$ 455$ and $\$ 50$, respectively). Similar analyses revealed no differences between the two groups on any of the subscales of the MAACL (all $p s>.20$ ). In addition, all within-cell 
correlations between the bond decisions and the various MAACL subscales were nonsignificant.

The major finding of Experiment 1 was that, as predicted, reminding subjects of their mortality led them to recommend higher bonds for an accused prostitute. According to terror management theory, moral principles are part of the cultural anxiety-buffer that protects individuals from anxiety concerning their vulnerability and mortality. Transgressions against these standards implicitly threaten the integrity of the anxietybuffer and thus engender negative reactions toward the transgressor. Inducing subjects to think about their mortality presumably increased their need for faith in their values, and thus increased their desire to punish the moral transgressor.

An obvious alternative explanation for these results is that judges in the mortality-salience condition were simply put in a bad mood and that bad mood predisposed the judges to treat the defendant harshly (cf. Veitch \& Griffitt, 1976). This explanation is rendered unlikely, however, by the lack of significant differences between groups on any of the MAACL subscales. Nonetheless, one of the goals of Experiment 2 was to assess this alternative.

\section{Experiment 2}

The central purpose of Experiment 2 was to test a more refined prediction of terror management theory. Although, for the sake of simplicity, we have discussed the cultural worldview as the conception of reality shared by all within a culture, in actuality each individual within a culture has his or her own understanding of the cultural worldview. Although most individuals within a culture are likely to share many basic assumptions and values, on the basis of individual experiences, perceptions, and interpretations each individual invests in a unique version of the cultural worldview. Theoretically, the individual's own version of the cultural worldview provides the basis for equanimity. Thus, the increased punishment found in Experiment 1's mortality-salient condition should occur primarily among subjects who have relatively negative attitudes toward prostitution. To test this hypothesis, we included a premeasure of attitudes toward prostitution in Experiment 2.

A second purpose of this experiment was to further examine the mood alternative. If the results of Experiment 1 resulted simply from a negative mood state created by the mortalitysalience manipulation, it follows that subjects' tendency to react negatively toward others would not be limited to those who had violated cultural norms but would extend to any target. To assess this possibility, we asked subjects in this experiment to evaluate the experimenter, who had not violated any social or cultural rules. If Experiment 1's findings resulted from a simple association of the target with a negative mood state, then subjects should derogate the experimenter as well as the hypothetical defendant; indeed, they might derogate the experimenter more because she gave them the death questionnaire.

\section{Method}

Subjects. Subjects were 31 male and 47 female college students who participated in the study during a class period of a research methods course. Of these subjects, the 22 men and 29 women with the most posi- tive and negative attitudes toward prostitution (upper and lower thirds) were used in the primary analysis.

Procedure. With the exception of the following changes, the procedure was identical to that of Experiment 1. First, rather than giving subjects the materials to return to the experimenter at their convenience, the materials were distributed and collected during the class period. Second, the cover story was somewhat more general. The expressed purpose of the study was to investigate how personality variables and attitudes affect people's decisions and evaluations of various stimuli. Third, because most college students know relatively little about the law relevant to setting bond, subjects were provided with a written explanation of the bond-setting process before they proceeded to the filler questionnaires. This explanation included a summary of relevant legal terms and a statement that bond for this class of offense usually ranges from $\$ 0$ to $\$ 999$.

More important, a measure of attitude toward prostitution was included in Experiment 2 among the filler questionnaires. The Prostitution Attitude Scale consisted of ratings of five statements concerning prostitution ( 3 anti, 2 pro) on 10-point scales, ranging from strongly agree to strongly disagree. A factor analysis of this scale revealed only one factor, with all five items loading .70 or higher. The distribution of scores on the attitude-toward-prostitution measure was divided into thirds, and subjects in the upper and lower tertile were included in the analysis as those with positive and negative attitudes toward prostitution, respectively.

Finally, once the experimenter had apparently completed the study and left the room, the course instructor passed out the Interpersonal Judgment Scale (IJS; Byrne, 1971) and told subjects that the study was designed in part to assess people's reactions to the experimenter. The IJS asked subjects to rate the extent to which they liked the experimenter, would like to work with her on an additional task, and viewed her as intelligent, moral, knowledgeable, and well adjusted. After all the written materials were collected, the subjects were thoroughly debriefed by the course instructor.

\section{Results and Discussion}

The primary analyses were 2 (mortality salience) $\times 2$ (attitude toward prostitution) ANOvAs. ${ }^{3}$ As in Experiment 1 , a highly significant main effect of mortality salience emerged on the bond measure, $F(1,47)=8.77, p<.003$, such that the bond allotted the prostitute was higher in the mortality-salient condition than in the control condition $(M s=\$ 283$ and $\$ 132$, respectively. More important, the predicted Attitude Toward Prostitution $\times$ Mortality Salience interaction was also found, $F(1,47)=$ $6.28, p<.02$. As can be seen in Table 1 , subjects with unfavorable attitudes toward prostitution assigned the prostitutes a significantly higher bond when mortality was salient than when it was not, $t(23)=3.77, p<.001$; mortality-salient-unfavorableattitude subjects also assigned a harsher bond than did mortality-salient-favorable-attitude subjects, $t(26)=3.27, p<.01$. Mortality salience had no reliable effect on the bond recommendations of subjects with relatively favorable attitudes toward prostitution.

A similar two-way ANOVA on the affect measures, the individual IJS items, and the total IJS scale (filled out with reference to the experimenter) revealed no effects that approached sig-

\footnotetext{
${ }^{3}$ For Studies 2, 3, 4, 5, and 6, initial ANOVAs including sex as an independent variable were conducted on the primary dependent variables. These analyses revealed no main effects or interactions involving sex.
} 
Table 1

Mean Bond Assessments for Study 2 Interaction Between Mortality Salience and Attitude Toward Prostitution

\begin{tabular}{ccc}
\hline Attitude toward prostitution & $\begin{array}{c}\text { Mortality } \\
\text { salient }\end{array}$ & $\begin{array}{r}\text { Mortality } \\
\text { nonsalient }\end{array}$ \\
\hline Favorable & $145.83_{\mathrm{b}}$ & $117.86_{\mathrm{b}}$ \\
Unfavorable & $413.88_{\mathrm{a}}$ & $78.11_{\mathrm{b}}$ \\
\hline
\end{tabular}

Note. Means that do not share a subscript differ at $p<.01$.

nificance (all $F \mathrm{~S}<1$ ). We also conducted four analyses of covariance (ANCOVAS) using each of the MAACL subscales as a covariate on the bond assessment. If the effects of mortality salience are mediated by mood, then the Attitude Toward Prostitution $X$ Mortality Salience interaction should either no longer be found or be severely attenuated in one or more of the covariance analyses. This was not found; all of the ANCOVAs revealed the same significant interaction (all $p s<.05$ ). Thus, the effect of mortality salience on bond recommendation is unlikely to be mediated by affect and does not seem to reflect a general tendency to respond negatively toward others when mortality is made salient.

Experiment 2 replicated Experiment 1's results and extended them in two important ways. First, the findings show that increasing the salience of mortality does not lead subjects to derogate just any target. Although mortality salience led to harsher bond assessments for the prostitute, it had no effect on evaluations of the experimenter. This, of course, is consistent with the notion that heightened awareness of mortality leads to greater need to defend the cultural anxiety-buffer. This finding, along with the absence of effects of mortality salience on the postmanipulation mood measures, further reduces the plausibility of mood as an alternative explanation.

In addition, as terror management theory suggests, mortality salience increased punishment of the transgressor only among subjects who believed that the target's behavior was truly immoral. The bond assessments of subjects with relatively positive attitudes toward prostitution were not affected by mortality salience because they did not see the prostitute's behavior as a violation of important values.

\section{Experiment 3}

An important implication of terror management theory is that mortality salience should not only increase subjects' desire to punish a moral transgressor, but also increase their desire to reward someone who upholds cultural values. When another person upholds cultural values, it provides consensual validation of those values and thus helps individuals maintain faith in them. The theory predicts that people will be especially prone to react positively to those who uphold cultural values when they are in need of the cultural anxiety-buffer, as is the case when they are reminded of their mortality. To test this hypothesis, we gave subjects the opportunity to recommend the amount of reward to be given to someone who had, at risk to herself, provided police with a tip that led to the apprehension of a criminal.

\section{Method}

Subjects. Subjects were 13 male and 19 female students in a research methodology course who participated in the study on the first day of class.

Procedure. The procedure and measures were the same as in the Experiment 2, except for the following changes. The IJS for the experimenter was not included. In addition to making bond assessments for the alleged prostitute, subjects were asked to recommend a reward for a woman who helped police apprehend a criminal. The reward-assessment questionnaire described a series of brutal muggings. It explained that several of the victims had suffered grave injuries, and that some had nearly died. The mugger had not been apprehended by police until a woman who lived next door to the criminal called a crime hotline because she believed her neighbor was the mugger. The woman called the hotline even though she was afraid of what the violent criminal would do if he found out that she had turned him in. The subjects were further informed that the reward for tips leading to an arrest is usually between $\$ 50$ and $\$ 10,000$. Subjects were asked to indicate the amount in dollars that they thought the woman should be rewarded.

As in previous studies, the bond and reward assessments were made after subjects had filled out a packet of questionnaires containing, for half of the subjects, the mortality-salience manipulation. The order of bond and reward assessments was counterbalanced.

\section{Results and Discussion}

Separate 2 (mortality salience) $\times 2$ (order of presentation) ANOVAS were conducted on subjects' bond assessments for the prostitute and reward recommendations for the hero. There were no main effects or interactions involving order. Consistent with the findings from Experiments 1 and 2, a main effect of mortality salience on bond recommendation showed that subjects in the mortality-salient condition recommended a higher bond for the prostitute than did subjects in the control condition $(M \mathrm{~s}=\$ 438$ and $\$ 134$, respectively), $F(1,31)=23.12, p<$ .0001 . In addition, a main effect of mortality salience on reward showed that mortality-salient subjects recommended a greater reward for the hero than did control subjects $(M s=\$ 3476$ and $\$ 1,112$, respectively), $F(1,31)=15.36, p<.0005$. Thus, reminding subjects of their mortality increased their desire not only to punish a moral transgressor, but also to reward a hero.

Consistent with Study 2, favorability of attitudes toward prostitution was negatively correlated with bond magnitude in the morality-salient condition, $r(17)=-.32$, although this correlation was not significant; in the control condition, the correlation was much smaller, $r(16)=-.07$.

These findings provide another replication of the effect of mortality salience on punishment of moral transgressors, and also demonstrate a predicted effect on rewards given to a person who upholds cultural values. Once again, analyses of the MAACL subscales revealed no evidence that mood mediated the effects on the primary dependent measures.

\section{Experiment 4}

The first 3 studies established a robust tendency for individuals who have been led to think about their own mortality to recommend especially harsh punishment for a prostitute. Study 2 showed that this effect occurs primarily among those with relatively negative views of prostitution. Thus, the effect seems to 
occur only when the target is truly viewed as a moral transgressor within the context of the individual's version of the cultural worldview. Study 2 also showed that mortality salience did not encourage negative evaluations of the experimenter. Study 3 showed that mortality salience encourages higher reward for a hero as well as harsher punishment for a prostitute.

Across the three studies, there was no evidence that the mortality-salience manipulation altered mood; mood is therefore an unlikely basis for an alternative explanation of the results. Three other findings also contraindicate a mood alternative: (a) only those with a negative attitude toward prostitution recommended a high bond in the mortality-salience condition; (b) mortality salience did not lead to negative evaluations of the experimenter; and (c) mortality salience led to positive treatment of the hero, which would be an unlikely result of a bad mood.

Whereas these data virtually eliminate mood as an alternative, a few other potential alternative explanations warrant consideration. One is a self-awareness explanation. If self-awareness encourages individuals to behave in a manner that is consistent with their attitudes and standards (for reviews, see Carver \& Scheier, 1981; Wicklund, 1975), perhaps the results from the previous experiments could be attributed to an increase in self-awareness brought on by the death questionnaire. To test between this explanation and the terror management explanation, subjects in Experiment 4 were asked to set bond for the prostitute under conditions of high or low self-awareness, as well as under the high or low mortality-salience conditions used in the previous studies. If the effects of mortality salience are mediated by heightened self-awareness, then subjects in a high self-awareness condition (created by the most reliable selffocusing stimulus, a mirror) should set a higher bond than subjects in a low self-awareness condition.

Another alternative explanation for the effects found so far might be that the death questionnaire creates arousal, which under some conditions has been shown to intensify reactions to both positive and negative stimuli (e.g., Paulhus, 1987; White, Fishbein, \& Rutstein, 1981; Zillman, 1971). A number of our findings cast doubt on the notion that arousal mediates these effects. First, excitation transfer effects are assumed to be mediated by intensification of affect; there was no evidence that the death questionnaire reliably increased affect. Second, excitation transfer effects only occur at specific points in time after the initial arousing event (when the individual is still aroused but no longer aware of it). The timing between the death questionnaire and the dependent measure was not controlled in any of the three studies; thus, the rather specific timing prerequisites for excitation transfer effects were unlikely to have been met. In addition, in Study 3 the order in which the measures were filled out (and therefore the amount of time between the manipulation and the dependent measure) did not modify the effect of mortality salience. These facts make it extremely unlikely that excitation transfer could account for our findings. Still, the arousal amplification explanation warrants consideration.

If mortality-salience effects result from arousal, then responses to any positive or negative stimuli should be intensified. Terror management theory, on the other hand, predicts intensification of response only to stimuli that bolster or threaten the cultural worldview. Therefore, in Study 4, along with setting bond for the prostitute, subjects were asked to rate how much they liked five generally pleasant events and five generally unpleasant events. Finally, to assess whether mortality salience simply encourages inflated monetary estimates, subjects were also asked to estimate the value of eight consumer products.

\section{Method}

Subjects. Subjects were 39 male and 44 female students who participated in partial fulfillment of their introductory psychology research requirement.

Procedure. Three or four subjects arrived at the lab for each session. Subjects were given the same cover story as before. In addition, they were told that to ensure their anonymity, they would be given the questionnaires in separate cubicles. Subjects were asked to fill out the questionnaires in the order presented without skipping ahead or going back; they were also asked to return to the central room after they had completed all of the forms, put the forms in an envelope, and drop them in the data box.

Subjects were then told that the cubicles were being shared with other researchers, and consequently there was equipment for other studies in the cubicles. Subjects were asked not to touch any of the equipment and to ignore it. Subjects were then instructed to go into one of the four cubicles and begin working on the questionnaires. In each of the cubicles, there were a variety of objects lying around. In two of the cubicles there was also a 3-ft $\times$ 4-ft mirror positioned on the desk, leaning up against the back wall so that, when seated, the subject was looking directly at his or her image in the mirror. A handwritten sign taped to the top left corner of the mirror read "Please do not move this mirror." There were no mirrors in the other two cubicles.

Subjects' packets began with the usual bond instructions and filler questionnaires, followed by the death questionnaire for half the subjects. Then half the subjects were given the bond instructions and recommendation form, followed by a questionnaire that asked them to rate five positive and five negative events, on a scale ranging from 1 (absolutely hate it) to 9 (absolutely love it), and a questionnaire that asked them how much money each of four attractive consumer products was worth to them and how much money they would charge for four other products if they were selling them at a retail outlet. The other half of the subjects were asked to rate the positive and negative events and the consumer products and were then given the bond materials. The consumer products included such things as a television, a plane trip, a sofa, and a bicycle. The positive events included such things as eating at a favorite restaurant and getting a really good night's sleep; the negative events included sitting through a boring lecture and a dentist's hitting a nerve. When all subjects had returned to the central room, they were probed for suspicion and thoroughly debriefed.

\section{Results and Discussion}

Initial 2 (mortality salience) $\times 2$ (self-awareness) $\times 2$ (order of presentation) ANOVAS revealed no effect of order on any of the measures. Thus, order was ignored in the final analyses. Analysis of the bond assessments revealed only the expected main effect of mortality salience, $F(1,79)=116.54, p<.0001$, with the mortality-salient subjects setting higher bonds than the control subjects $(M \mathrm{~s}=\$ 537.84$ and $\$ 102.34$, respectively). There were no hints of either a main effect or an interaction involving self-awareness (both $p s>.14$ ).

Analyses of ratings of both individual items and composites of the positive- and negative-event items showed no effects approaching significance (all $p s>.20$ ). Analysis of a composite of the monetary value estimates also revealed no effects $(p>.20)$. 
Analyses of the affect scales revealed a significant mortalitysalience main effect on positive affect, $F(1,79)=10.76, p<$ .002 . Surprisingly, mortality-salient subjects reported more positive affect than did mortality-nonsalient subjects $(M s=$ 5.74 and 3.18 , respectively). Although such an effect did not occur in the previous experiments, we assessed the possibility that this affect difference mediated the bond effects by examining within-cells correlations and conducting an ANCOVA on bond assessments, using positive affect scores as a covariate. None of the within-cells correlations between affect scores and bond assessments approached significance. The ANCOVA showed the same main effect of mortality salience on bond assessments, $F(1,78)=95.09, p<.0001$. Thus, as in the prior experiments, affect did not seem to mediate the effect of mortality salience on bond assessments.

Although the $2 \times 2$ ANOVA did not reveal any effects of the mirror, self-awareness theory and research suggests that the mirror's effects may depend on attitudes toward prostitution. To investigate this possibility, as in Study 2 we categorized subjects as pro- or antiprostitution on the basis of whether they fell in the top or bottom third on the attitude-toward-prostitution premeasure. A subsequent $2 \times 2 \times 2$ ANOVA revealed the same main effects as the primary analysis. ${ }^{4}$ In addition, a marginal Mortality Salience $\times$ Attitude Toward Prostitution interaction was found, $F(1,47)=3.70, p<.06$. As the means in Table 2 indicate, mortality salience encouraged harsher treatment by the unfavorable-attitude subjects than by the favorable-attitude subjects, $t(26)=1.91, p<.05$ (one-tailed), although even these latter subjects clearly displayed the basic effect. ${ }^{5}$

This analysis also revealed a significant Self-Awareness $\times$ Attitude interaction, $F(1,47)=4.37, p<.05$. The means in Table 3 for this interaction show that the effect of heightened selfawareness is quite different from the effect of mortality salience. Self-awareness did not encourage harsher treatment of the prostitute, even in the unfavorable-attitude condition, $t(26)<1$. In fact, favorable-attitude, high-self-aware subjects were more lenient than both favorable-attitude, low-self-aware subjects, $t(25)=3.03, p<.01$, and unfavorable-attitude, high-self-aware subjects, $t(27)=4.23, p<.01$.

The results of Study 4 indicate that unlike mortality salience, self-awareness does not encourage harsher bond recommendations. Rather, the evidence suggests that heightened self-awareness reduces the harshness of treatment of the prostitute among individuals with positive attitudes toward prostitution. This effect is consistent with the self-awareness literature in that relatively positive attitudes toward prostitution guided behavior only for subjects in the mirror condition (e.g., Carver, 1975).

Table 2

Mean Bond Assessments for Study 4 Interaction Between Mortality Salience and Attitude Toward Prostitution

\begin{tabular}{ccc}
\hline Attitude toward prostitution & $\begin{array}{c}\text { Mortality } \\
\text { salient }\end{array}$ & $\begin{array}{c}\text { Mortality } \\
\text { nonsalient }\end{array}$ \\
\hline Favorable & $454.45_{\mathrm{b}}$ & $98.44_{\mathrm{c}}$ \\
Unfavorable & $575.00_{\mathrm{a}}$ & $82.55_{\mathrm{c}}$ \\
\hline
\end{tabular}

Note. Means that do not share a subscript differ at $p<.05$ (one-tailed).
Table 3

Mean Bond Assessments for Study 4 Interaction Between

Self-Awareness and Attitude Toward Prostitution

\begin{tabular}{ccc}
\hline Attitude toward prostitution & $\begin{array}{c}\text { High } \\
\text { self-awareness }\end{array}$ & $\begin{array}{c}\text { Low } \\
\text { self-awareness }\end{array}$ \\
\hline Favorable & $144.23_{\mathrm{b}}$ & $335.64_{\mathrm{a}}$ \\
Unfavorable & $404.69_{\mathrm{a}}$ & $350.67_{\mathrm{a}}$ \\
\hline
\end{tabular}

Note. Means that do not share a subscript differ at $p<.01$.

In addition, Study 4 showed that mortality salience does not simply amplify monetary estimates or reactions to any positive or negative stimuli, thus casting doubt on an arousal explanation. However, one could argue that the descriptions of positive and negative events were not sufficiently realistic or vivid to create affective reactions; therefore, the preconditions for arousal to intensify affective reactions may not have been met.

\section{Experiment 5}

A more conclusive way to test between arousal amplification and terror management explanations would be to replicate the effect while monitoring indicators of physiological arousal. Study 5 was designed to do just that. We expected that the death questionnaire would lead to harsh bond assessments, but would not create greater physiological arousal than control conditions. In Study 5, two control conditions were included, one that simply omitted the death questionnaire, as in the prior experiments, and one that included a questionnaire paralleling it, which asked subjects to describe what happens when they eat and what emotions the thought of food arouses in them. This latter control condition more closely parallels the task required in the death-questionnaire condition by controlling for the amount of writing requested of the subjects.

\section{Method}

Subjects. Eighteen female and 18 male college students volunteered to participate in the experiment in exchange for a $\$ 5$ payment. Subjects were seated at a desk in a straight-backed chair during the experiment.

Procedure. Subjects were run individually. On arriving for the appointment, the experimenters greeted subjects and gave them a tour of the lab. Subjects were then seated in the experimental room and told that the experiment was concerned with psychological and physiological factors that influence the way people make decisions. In an adjoining control room, a Grass Instruments Company physiograph was used to record physiological responses. Subjects were then given an informedconsent form to read and sign.

The consent form reiterated the general purpose of the study, and also informed subjects that we were specifically interested in the role that

\footnotetext{
${ }^{4}$ We should note that this analysis involved only 55 subjects. Thus, the cell sizes for the three-way interaction were unacceptably small. However, the two-way interactions were the interactions of interest here; the lowest cell $n$ for either of the two-way interactions was 11 .

${ }^{5}$ Attitudes toward prostitution were somewhat more unfavorable in Study 4 than in Study 2, with means of 23.07 and 24.68, respectively. This may have contributed to the weaker interaction pattern found in Study 4 .
} 
various personality characteristics play in decision making and how different levels of physiological arousal influence decisions. Accordingly, subjects were asked to complete a series of questionnaires and then make a judicial decision in a simulated legal case, while we measured their physiological responses.

Once subjects signed the consent form, the second and fourth fingertips of their nondominant hands were cleansed with alcohol pads and gently filed with an emery board. Beckman skin resistance electrodes were then attached to their fingertips, and their function was briefly explained. A Grass Instruments finger pulse transducer was then placed on the middle finger of the nondominant hand. Subjects were told that this would allow us to measure their pulse rates, as well as peripheral blood volume (pulse volume).

Tape-recorded instructions were then started by the experimenter in the control room. Subjects were told that the experiment that they were participating in would occur in several stages. The first stage would be a rest period in which baseline physiological measures would be obtained. Later, they would complete a series of personality measures, followed by a description of a hypothetical judicial case about which they would be asked to make a decision. Subjects were then told that physiological measurements would be taken throughout the study.

After the 5-min rest period, the experimenter returned to the room and placed a poster containing some information about the upcoming judicial decision on the desk in front of the subjects. Subjects were informed that they would be asked to refer to this information in a short time. This information was the same as was provided to subjects in each of previous experiments. The experimenter then returned to the control room and the tape-recorded instructions resumed.

Subjects were instructed to complete a series of personality measures on the desk in front of them. Each packet had the usual filler questionnaires. The next questionnaire varied according to experimental conditions. In the mortality-salience condition, we used the same questionnaire as in the prior experiments. In the eating-salience condition, the fifth questionnaire contained two parallel open-ended questions that pertained to food and eating rather than to death. In the no-questionnaire control condition, neither questionnaire was included. As in the prior experiments, the experimenter was blind to each subject's condition. At this time, subjects were informed that there would be a 1-min waiting period, presumably to recalibrate the physiological equipment before the judicial-decision phase of the experiment. This period was actually used to collect the physiological dependent measures.

Subjects were then asked to consider the same information about the alleged prostitute used in the previous experiments. Subjects were asked to consider all of this information carefully, and to then set bond for the alleged prostitute. Subjects were reminded that they could refer at any time to the legal information on the poster that the experimenter had previously placed before them. As in the prior experiments, bond assessments were made in response to an open-ended question on the final page of the packet. Once completed, subjects were disconnected from the physiograph, probed for suspicion, and thoroughly debriefed.

\section{Results and Discussion}

Bond assessment. The mean bond assessments for subjects in each condition are presented in Table 4. A one-way ANOVA revealed significant differences between conditions, $F(2,33)=$ $4.55, p<.02$. Planned pairwise comparisons revealed that subjects in the mortality-salient condition set reliably higher bonds than subjects in either the eating-salient condition, $t(24)=2.83$, $p<.005$, or the no-questionnaire control condition, $t(24)=$ $2.05, p<.05$. Not surprisingly, a planned comparison between the mortality-salient condition and the two control conditions combined was highly significant, $t(34)=2.94, p<.01$. The
Table 4

Mean Bond Assessments and Adjusted Scores for

Physiological Measures in Study 5

\begin{tabular}{lccc}
\hline \multicolumn{1}{c}{ Measure } & $\begin{array}{c}\text { Mortality } \\
\text { salient }\end{array}$ & $\begin{array}{c}\text { Eating } \\
\text { salient }\end{array}$ & $\begin{array}{c}\text { No } \\
\text { questionnaire }\end{array}$ \\
\hline Bond assessments & $474_{\mathrm{a}}$ & $220_{\mathrm{b}}$ & $290_{\mathrm{b}}$ \\
Pulse rate & $36.13_{\mathrm{c}}$ & $36.19_{\mathrm{c}}$ & $33.68_{\mathrm{c}}$ \\
Pulse volume & $364.46_{\mathrm{d}}$ & $527.47_{\mathrm{d}}$ & $377.89_{\mathrm{d}}$ \\
Skin resistance & $933.3 \mathrm{I}_{\mathrm{c}}$ & $968.59_{\mathrm{c}}$ & $1107.24_{\mathrm{c}}$ \\
\hline
\end{tabular}

Note. For pulse rate, a higher number is indicative of greater arousal. For pulse volume and skin resistance, a lower number is indicative of greater arousal. Within each measure, means that do not share subscripts differ at $p<.05$.

bonds set by subjects in the eating-salient and no-questionnaire control conditions were not significantly different $(M s=220$ and 290 , respectively), $t(18)=.70, p>.5$. Thus, the usual effect was replicated.

Scoring and preparation of physiological data. Pulse rate, pulse volume, and skin resistance were scored for two 30-s periods. The first period was the last $30 \mathrm{~s}$ of the rest period that preceded any of the experimental manipulations. Measures taken during that period were used as measures of subjects' initial levels of arousal. The second period was the last $30 \mathrm{~s}$ of the 1-min period after the experimental manipulations, but before the consideration of the bond assessments. Pulse-rate data were scored by simply counting the number of beats occurring during each period. Pulse volume and skin resistance were scored by determining the lowest level of arousal (highest pulse volume and skin resistance) during the first period, and the highest level of arousal (lowest pulse volume and skin resistance) during the second period.

Results of analysis of physiological data. There were no premanipulation differences on the physiological measures; still, to eliminate the influence of initial levels of arousal on subsequent levels of arousal (i.e., the "law of initial values"; Lacey, 1956; Wilder, 1962), ANCOVAs were performed on each of the physiological measures, using the appropriate scores from the rest period as the measures of initial levels of arousal. The adjusted pulse rate, pulse volume, and skin resistance scores for each condition are presented in Table 4 . As predicted, the covariance analyses revealed no significant differences between conditions for any of the physiological measures: pulse rate, $F(2,32)=$ $2.49, p=.09$; pulse volume, $F(2,32)=1.27, p=.29$; skin resistance, $F(2,32)=0.59, p=.56$. It should be noted that the marginally significant effect for pulse rate does not reflect the same pattern of results found for the bond assessments. Instead, the mean pulse rate for subjects in both the mortality- and eatingsalient conditions seems to be higher than the pulse rate for subjects in the no-questionnaire condition.

To assess the possibility that arousal mediated the mortalitysalience effect even in the absence of significant arousal effects paralleling the bond assessments, we examined within-cells correlations and conducted ANCOVAS using both the raw postmanipulation physiological measures and the residual scores derived from regressing the premeasures on the postmeasures. None of the 18 within-cells correlations between arousal mea- 
sures and the bond approached significance (all $p s>.10$ ). In addition, the mortality-salience main effect remained significant for all six of the ANCOVAs (all $p s<.05$ ). Clearly then, physiological arousal cannot account for the mortality-salience effects.

\section{Experiment 6}

There are two important methodological commonalities that limit the generality of the foregoing experiments. The first is that they all used the same dependent measure: bond for a prostitute. In another set of studies, however, we have found mortality-salience effects on a variety of evaluations concerning a variety of targets (Greenberg et al., 1989). These experiments are briefly described in the General Discussion. The second commonality is that all of the experiments used the same mortalitysalience treatment. We designed Experiment 6 simply to establish whether another mortality-salience treatment would replicate the bond effect. Thus, in this experiment, rather than answering two open-ended questions about their own death, mortality-salient subjects completed Boyar's (1964) Fear of Death Scale, which uses a Likert format. Control subjects completed the A-Trait form of the State-Trait Anxiety Inventory (Speilberger, Gorsuch, \& Lushene, 1970). The other materials used were the usual filler questionnaires and the prostitute bond instructions and recommendation form.

\section{Method}

Subjects. Subjects were 19 female and 15 male students, who participated in the study during a class period of a statistics course.

Procedure. Questionnaire packets were distributed at the beginning of the class period and collected at the end. The packets consisted of the same bond instructions, filler questionnaires, MAACL, information about the prostitute, and bond recommendation form. Following the filler questionnaires and before the MAACL, subjects filled out either the Fear of Death Scale (Boyar, 1964) or the A-Trait form of the State-Trait Anxiety Inventory (Spielberger et al., 1970). The Fear of Death Scale consists of 18 statements about death (e.g., "The idea of never thinking again after I die frightens me"; "Never again feeling anything when I die upsets me"). When all subjects were done, they were probed for suspicion and fully debriefed.

\section{Results and Discussion}

As expected, a one-way ANOVA found an effect of mortality salience, $F(1,32)=14.98, p<.0005$, such that mortality-salient subjects recommended a much higher bond $(M=\$ 400.33)$ than did mortality-nonsalient subjects $(M=\$ 99.94)$. Analyses of the MAACL subscales revealed no effects approaching significance (all $p s>.10$. Experiment 6 thus established that the effects found in the previous five studies are not due to the particular features of the open-ended death questionnaire, but rather to requiring the subjects to think about their own deaths.

\section{General Discussion}

Taken together, the six studies reported in this article provide consistent support for terror management theory hypotheses concerning reactions to those who deviate from cultural standards. In all six experiments, subjects who were reminded of their mortality consistently recommended harsher treatment of a moral transgressor. Experiment 1 showed that even municipal court judges with a great deal of legal training succumb to this effect. Experiment 2 demonstrated that this effect does not appear to reflect a general bias toward negative evaluations of others; mortality salience had no effect whatsoever on evaluations of the experimenter. Experiment 2 also demonstrated that mortality salience increased negative reactions to deviant persons only among those who hold negative attitudes toward the particular type of deviance in question. Thus it appears that it is the individual's own unique version of the cultural worldview that must be defended against threat. Experiment 3 replicated the effect of mortality salience on reactions to deviant persons and also demonstrated that mortality salience increases the tendency to respond positively toward individuals who uphold cultural values.

Experiment 4 demonstrated that the effects of our mortalitysalience manipulation do not parallel those produced by a selfawareness manipulation and do not simply reflect an amplification of responses to any affectively significant stimulus. Experiment 5 demonstrated that the mortality-salience manipulation does not produce measurable increases in physiological arousal (as assessed by pulse rate, pulse volume, and skin conductance) and that variations in physiological arousal do not appear to mediate the effect of mortality salience on responses to moral transgressors. Experiment 5 also showed that the noquestionnaire control condition used in the prior four experiments is equivalent to a more parallel control condition in which subjects were asked to write about eating. Finally, Experiment 6 replicated the mortality-salience effect with a different mortality-salience treatment and a different control group.

According to terror management theory, the beliefs and values that make up an individual's cultural worldview serve the vital function of buffering the anxiety that results from awareness of human vulnerability and mortality. The theory posits that the cultural worldview espoused by any given individual is a fragile construction that needs persistent social validation if the individual is to maintain faith in it. Those who deviate from cultural standards are responded to with disdain because such behavior threatens the values that underlie the individual's source of security. Similarly, those who uphold cultural values are admired because such behavior validates the individual's values.

The present finding that reminding subjects of their mortality intensifies such reactions supports the proposition that the cultural worldview serves to protect individuals from anxiety concerning death. Theoretically, reminding subjects of their mortality increases their need for the protection from anxiety that their cultural worldview provides. Consequently, mortality salience leads to more negative reactions toward those who undermine the cultural worldview and more positive reactions toward those who uphold it.

The basic finding that mortality salience increases rejection of moral transgressors is consistent with the proposition that moral principles are part of the configuration of beliefs and values that protect the individual from anxiety concerning his or her mortality. For many people, moral principles are embedded in a more general system of religious beliefs that very explicitly provides hope of transcending death and insignificance. In addi- 
tion to their explicit link to religious beliefs, moral principles are part of the more general set of cultural standards against which people compare themselves to assess their value. Thus, moral principles facilitate the individual's efforts to conceive of him- or herself as a valued contributor to something meaningful and permanent (the culture).

Interestingly, across all six experiments, there was no hint that the effects of mortality salience depend on physiological arousal or the conscious experience of anxiety. This largely rules out alternative explanations based on the arousal-based amplification of dominant responses (cf. Paulhus \& Levitt, 1987). These findings raise the question, however, of why no signs of affect or arousal were detected in response to our mortalitysalience manipulation, in spite of its consistent effects on evaluations of those who impinge on the cultural worldview.

In accord with Becker (1973) and others (e.g., Yalom, 1980; Zilboorg, 1943), terror management theory posits that by maintaining the two components of the cultural anxiety-buffer, individuals are shielded from the intense anxiety, or terror, associated with the awareness of vulnerability and mortality. ${ }^{6}$ In other words, the cultural anxiety-buffer allows continual repression of our existential terror (see Solomon et al., 1989, in press). Thus, we propose that terror management needs constantly guide behavior, but that individuals are not necessarily consciously concerned with their own deaths on a day-to-day basis.

Although the terror may on occasion rise to consciousness in muted form, most of the anxiety people experience results from threats to either the worldview or self-esteem components of the cultural anxiety-buffer that protects them from the underlying existential terror. By bolstering and defending these two components, people can bypass the conscious experience of emotion that reminders of mortality would otherwise create. As Greenwald (1989) has recently argued (from a very different perspective), defensive reactions may sometimes occur so quickly and effectively that the subjective experience of anxiety is completely circumvented. Although the present findings provide strong support for hypotheses derived from terror management theory, there is clearly a need for investigation of the precise intrapsychic mechanisms by which terror management occurs.

Terror management theory is an extremely broad perspective with implications for diverse areas of traditional social psychological inquiry. Because of the wide variety of hypotheses that can be derived from the theory, the present research must be viewed as just a first step in testing it. We believe that one of the most appealing aspects of the theory is the broad range of testable hypotheses that it can be used to generate. In fact, we have already gathered substantial evidence concerning two other sets of hypotheses.

The first set of hypotheses also concerned reactions to those who threaten or bolster the cultural worldview. The theory suggests that individuals should not only reward those who uphold basic values and punish those who violate them, but should also react positively to anyone who implicitly or explicitly validates the individual's cultural worldview and react negatively to anyone who implicitly or explicitly threatens it. Clearly, similar others, in-group persons, and those who explicitly praise the culture help validate the individual's cultural worldview, and dissimilar others, out-group persons, and those who criticize the culture threaten its validity. From the perspective of terror man- agement theory, it is no coincidence that, generally, the former types of people are reacted to positively and the latter types are reacted to negatively. If terror management plays a role in these reactions, they should be intensified by mortality salience. We recently reported three studies that found consistent support for this hypothesis (Greenberg et al., 1989). In the first study, mortality salience led Christian subjects to evaluate a fellow Christian (an in-group person) especially positively and a Jew (an out-group person) especially negatively. In the second study, mortality salience led high authoritarian subjects (who tend to be rigid in their views) to react particularly negatively toward an attitudinally dissimilar other. In the third study, mortalitysalient (American) subjects reacted especially favorably to statements that praised the United States and especially negatively to statements that criticized the United States.

Although most of the studies we have conducted thus far have concerned the cultural worldview component of the anxiety buffer, we have also recently completed three studies examining the self-esteem component. In all three studies, we raised selfesteem or left it alone, exposed subjects to threatening or nonthreatening stimuli, and measured anxiety. If self-esteem serves an anxiety-buffering function, then increased-self-esteem subjects should experience less anxiety in response to threat than neutral-self-esteem subjects. Two of the studies showed that when threatened with shock, increased-self-esteem subjects had smaller galvanic skin responses than neutral-self-esteem subjects. The third study showed that when exposed to gory, videotaped scenes of death, increased-self-esteem subjects reported less anxiety on the Speilberger A-State (Spielberger et al., 1970) than did neutral-self-esteem subjects. We are currently assessing alternative explanations of these effects.

Perhaps more important than the findings of this research, however, are the challenging and neglected questions concerning the functions of culture, values, and self-esteem that the theory leads one to consider. These initial findings suggest that further investigation of these questions and the answers to them offered by terror management theory is clearly warranted.

\footnotetext{
${ }^{6}$ Although repression has been a difficult phenomenon to demonstrate unequivocally (D. J. Holmes, 1974), a number of recent studies have provided evidence that suggests that motivated forgetting of emotionally significant events does, in fact, occur (e.g., Davis, 1987; Davis \& Schwartz, 1987; Hansen \& Hansen, 1988). Hansen and Hansen's (1988) data suggest that such effects are especially pronounced for fearrelated memories. These findings are generally consistent with the terror management position.
}

\section{References}

Beck, A. T. (1967). Depression: Clinical, experimental, and theoretical aspects. New York: Harper \& Row.

Becker, E. (1962). The birth and death of meaning. New York: Free Press.

Becker, E. (1973). The denial of death. New York: Free Press.

Becker, E. (1975). Escape from evil. New York: Free Press.

Boyar, J. I. (1964). The construction and partial validation of a scale for the measurement of the fear of death. Dissertation Abstracts, 25, 20 21.

Byrne, D. (1971). The attraction paradigm. New York: Academic Press. Carver, C. S. (1975). Physical aggression as a function of objective self- 
awareness and attitude toward punishment. Journal of Experimental Social Psychology, 11, 510-519.

Carver, C. S., \& Scheier, M. (1981). Attention and self-regulation. New York: Springer-Verlag.

Davis, P. J. (1987). Repression and the inaccessibility of affective memories. Journal of Personality and Social Psychology, 53, 585-593.

Davis, P. J., \& Schwartz, G. E. (1987). Repression and the inaccessibility of affective memories. Journal of Personality and Social Psychology, $52,155-162$.

Festinger, L. (1954). A theory of social comparison processes. Human Relationships, 1, 117-140.

Greenberg, J., Pyszczynski, T., \& Solomon, S. (1986). The causes and consequences of a need for self-esteem: A terror management theory. In R. F. Baumeister (Ed.), Public self and private self(pp. 189-212). New York: Springer-Verlag.

Greenberg, J., Pyszczynski, T., \& Solomon, S. (1989). Evidence for terror management theory: II. The effects of mortality salience on reactions to those who threaten or support the cultural worldview. Unpublished manuscript, University of Arizona.

Greenwald, A. G. (1989). Self-knowledge and self-deception. In J. S. Lockard \& D. L. Paulhus (Eds.), Self-deception: An adaptive mechanism? (pp. 113-131). New York: Prentice-Hall.

Hansen, R. D., \& Hansen, C. H. (1988). Repression of emotionally tagged memories: The architecture of less complex emotions. Journal of Personality and Social Psychology, 55, 811-818.

Holmes, D. J. (1974). Investigation of repression: Differential recall of material experimentally or naturally associated with ego threat. Psychological Bulletin, 81, 632-653.

Holmes, T. H., \& Rahe, R. E. (1967). The social readjustment rating scale. Journal of Psychosomatic Research, 11, 213-218.

Kelley, J. (1967). Attribution theory in social psychology. In D. Levine (Ed.), Nebraska Symposium on motivation (pp. 192-238). Lincoln: University of Nebraska Press.

Lacey, J. (1956). The evaluation of autonomic responses: Toward a general solution. Annals of the New York Academy of Science, 67, 123164.

Miller, C. E., \& Anderson, P. D. (1979). Group decision rules and the rejection of deviates. Social Psychology Quarterly, 42, 354-363.

Paulhus, D. L. (1987). A dynamic complexity model of personality processes. Unpublished manuscript, University of British Columbia.
Paulhus, D. L., \& Levitt, K. (1987). Desirable responding triggered by affect: Automatic egotism? Journal of Personality and Social Psychology, 52, 245-259.

Schachter, S. (1951). Deviation, rejection and communication. Journal of Abnormal and Social Psychology, 46, 189-207.

Solomon, S., Greenberg, J., \& Pyszczynski, T. (1989). A terror management theory of self-esteem and its role in social behavior. Unpublished manuscript, Skidmore College.

Solomon, S., Greenberg, J., \& Pyszczynski, T. (in press). The critical role of self-esteem in adaption: A terror management analysis. In C. R. Snyder \& D. Forsyth (Eds.), Handbook of social and clinical psychology: The health perspective. New York: Pergamon Press.

Spielberger, C. D., Gorsuch, R. L., \& Lushene, R. E. (1970). Trait anxiety inventory (self-evaluation questionnaire). Palaupo, LA: Consulting Psychologist Press.

Veitch, R., \& Griffitt, W. (1976). Good news, bad news: Affective and interpersonal effects. Journal of Applied Social Psychology, 6, 69-75.

White, G. L., Fishbein, S., \& Rutstein, J. (1981). Passionate love and the misattribution of arousal. Journal of Personality and Social Psychology, 41, 56-62.

Wicklund, R. (1975). Objective self-awareness. In L. Berkowitz (Ed.), Advances in experimental social psychology (Vol. 8, pp. 233-275). New York: Academic Press.

Wilder, J. (1962). Basimetric approach (law of initial values) to biological rhythms. Annals of the New York Academy of Science, 98, 12111220.

Yalom, I. D. (1980). Existential psychotherapy. New York: Basic Books.

Zilboorg, G. (1943). Fear of death. Psychoanalytic Quarterly, 12, 465 475.

Zillmann, D. (1971). Excitation transfer in communication-mediated aggressive behavior. Journal of Experimental Social Psychology, 7, 419-434.

Zuckerman, M., \& Lubin, B. (1965). Manual for the Multiple Affect Adjective Check List. San Diego, CA: Educational \& Industrial Testing Service.
Received August 9, 1988

Revision received March 15, 1989

Accepted March 17, 1989 